\title{
Comparative Performance of Serial Collapsible Fish Trap Using Different Funnel Designs
}

\author{
D. Arunjenish", N. Neethiselvan, B. Sundaramoorthy, P. Jawahar and K. Masilan
}

Fisheries College and Research Institute, Tamil Nadu Dr. J. Jayalalithaa Fisheries University, Thoothukudi, Tamil Nadu-628008, India

*Corresponding author

\section{A B S T R A C T}

\section{Keywords}

Serial collapsible fish trap, Fishing trial, Catching efficiency, Funnel design

Article Info

Accepted:

04 July 2019

Available Online:

10 August 2019
The effectiveness of four different funnels such as Rectangular, Oval, heartin and Circular shaped funnels were tested in a serial collapsible fish trap through fishing trials conducted in a coastal fishing ground of Mandapam of Tamil Nadu, India. A total of 24 fishing operations were carried out. The significant difference in the overall catch rate of the experimental trap with respect to funnels could be observed $(\mathrm{P}<0.05)$. Among four types of funnels tested with the constant rear end funnel perimeter of $700 \mathrm{~mm}$, traps with Oval funnel caught high number of fishes (89 No's/24 soaking days) than those fitted with Rectangular, Heart-in shaped and Circular type of funnels with 34 No's/24 soaking days, 37 No's/24 soaking days and 15 No's/24 soaking days respectively. The study revealed that Oval shaped funnel was superior to the other shapes of funnels with $700 \mathrm{~mm}$ circumference.

\section{Introduction}

Various attempts have been made both in India and in the rest of the world to use trap as commercial fishing gear. Trap fishing is an excellent low energy fishing method compared to active fishing methods. The trap is an impounding device into which fishes are lured and afterward escapement is made difficult because of the presence of a nonreturn device fixed at the entrance (Bousten $e t$ al., 2005). Fish traps contribute significantly to fish catch especially when fishing is inevitable in more heterogeneous aquatic habitats including Fishing grounds with rocks, coral reefs and mangroves (Ferery and Kohler, 1987; Sheaves, 1996). West Indian type fish trap was the most popularly used fishing device in the Virgin Islands of the Caribbean Sea (Olsen et al., 1978). They reported that, among the catches from 10 different fishing gears of Virgin Islands, the catches from fish traps alone contributed as much as $80 \%$ of total fish catch

Development of the collapsible trap fishing technique is of recent origin. Caesar and Oxenford (2005) reported that the collapsible 
traps were found to catch significantly larger fishes than traditional traps. Collapsible traps have been found to be ideal for small scale fishing over the reef in East Nusa Tenggara province of Thailand (Hutubessy and Mosse, 2007). The collapsible traps were found successful in addressing the issue of safety and time efficiency at sea since more than twice the number of traditional traps could be carried and deployed from the small artisanal boats used in the Tobagonian deep demersal fishery of Caribbean sea (Caesor and oxenford, 2005).

The design of the entrance was found to be of great importance for the catching efficiency of the pots (Furevik and Lokkeborg, 1993; Mariappan et al., 2016). The present investigation deals with testing of the effectiveness of four different funnel designs such as Rectangular, Oval, Heart-in and Circular shaped funnels with $700 \mathrm{~mm}$ perimeter using the serial collapsible fish trap in the coastal fishing ground of Mandapam Coast of Tamil Nadu.

\section{Materials and Methods}

The present study was carried out for six months from November 2016 to April 2017. The traps were operated from a Vallam with the Length Overall (LOA) of $6.7 \mathrm{~m}$, the beam of $1.7 \mathrm{~m}$ and the depth of $1.2 \mathrm{~m}$. The experimental traps were operated in fishing grounds three nautical miles off the coast of Mandapam, Tamil Nadu, India (Fig. 1). The total soaking duration of the trap was kept as $24 \mathrm{hrs}$ for all fishing trials. Two units were fabricated. Each unit had two sections in serially connected condition by combining them in the form of a unit. The first unit under the experimental trap had rectangular shaped funnel in one section and oval-shaped funnel in another section (Fig. 2). The second unit had a heart-in shaped funnel in one section and circular shaped funnel in another section (Fig. 3). A pair of PVC rods with a length of
$90 \mathrm{~cm}$ each and another pair with the length of $60 \mathrm{~cm}$ were used for the fabrication of trap. The four pieces were joined together to form a rectangular frame by bolt and nut. Seven frames were used for making a serial trap so as to have six chambers per trap unit. Two such trap units were fabricated (Fig. 2 and 3). Blue polyethylene webbing of square meshes of $50 \mathrm{~mm}$ mesh size had 120 meshes in length and 80 meshes in height and was joined horizontally by folding their ends together so as to form a long bag and laced with a help of a polyethylene twine having the specification of 23 Tex $/ 2 / 3$. The inter-distance between two frames was kept as $0.56 \mathrm{~m}$ with 19 meshes. The front face of the trap had 40 meshes in length and 20 meshes in height. To make the collection bags at the end of the serial trap assembly, webbing having the dimensions of 112 meshes along the length and 50 meshes in height was seamed to form a single cylindrical bag. A $12 \mathrm{~mm}$ polyethylene rope was passed through the end meshes of the collection bag so as to enable closing and opening.

The front face of each of the trap units was cut and removed on the alternative side so that each of the adjacent traps had the entrance in the opposite side. Funnels of both units of traps were designed using polyethylene webbing of $30 \mathrm{~mm}$ mesh size made up of twine with a thickness of $0.25 \mathrm{~mm}$. A partition was made with polyethylene webbing in between $3^{\text {rd }}$ and $4^{\text {th }}$ frame so as to have two different sections in the serial trap to facilitate two types of funnels. A total of four shapes of funnels were fabricated. In the first trap assembly, the first section consisted of 3 chambers, each of which was fitted with Rectangular funnel while the three chambers of the $2^{\text {nd }}$ section were fitted with Oval funnels (Fig. 4 and 5). In the second trap assembly first, three chambers were fitted with Heart-in shaped funnels while the rest of the three chambers were fitted with Circular funnels (Fig. 6 and 7). To design rectangular funnel, 3 net panels were joined horizontally with 
different take-up ratio. The first panel consisted of 95 meshes in length and 11 meshes in depth. The second panel consisted of 46 meshes in length and 7 meshes in depth. Both first and second panels were joined with the take-up ratio of $2 / 1$. The third panel consisted of 31 meshes in length and 5 meshes in depth and it was joined with the second panel with take-up ratio of $3 / 2$. The Rectangular funnel had a base width of $5 \mathrm{~cm}$ (5 meshes) and a height of $23 \mathrm{~cm}$ (10 meshes) (Fig. 8). The four corners of Rectangular funnel were tied with the help of $2 \mathrm{~mm}$ polyethylene twine to the respective opposite corners of the trap chamber. The Rectangular funnel did not have any tilt at the rear end. However, all the other funnels were set to have tilt downwards. To facilitate this, an additional piece of webbing was provided in the rear end of the funnels. The fourth panel of Oval funnels had 19 meshes in length and 8 meshes in depth and it was joined with the third panel with the take-up ratio of $3 / 2$. The rear funnel opening of Oval funnels had the mid opening width of $11 \mathrm{~cm}$ (Fig. 9). To facilitate the oval mouth opening, an oval ring made up of $0.4 \mathrm{~cm}$ thick iron with the length of $56 \mathrm{~cm}$ was used. In the case of Heart-in shaped funnels, the fourth funnel had 22 meshes in length and 5.5 meshes in depth. It was joined with the third panel with the takeup ratio of 4/3. The rear opening of Heart-in shaped funnels had the mid opening width of $14 \mathrm{~cm}$ (Fig. 10). To facilitate the Heart-in shaped mouth opening, a Heart-in shaped ring made up of $0.4 \mathrm{~cm}$ thick iron with the length of $56 \mathrm{~cm}$ was used. In Circular funnels, the fourth panel had 13 meshes in length and 5 meshes in depth and it was connected to the third panel with the take-up ratio of $2 / 1$. The rear funnel opening of Circular funnels had a diameter of $18 \mathrm{~cm}$ (Fig. 11). To facilitate the circular mouth opening, a circular ring made up of $0.5 \mathrm{~cm}$ thick iron with the length of 56 $\mathrm{cm}$ was used. After lacing the lateral ends of the combined funnel piece, the rear end funnel circumference was maintained as $56 \mathrm{~cm}$ for all four types of entrances.

\section{Results and Discussion}

In the present study, four different funnels namely Rectangular, Oval, heart-in, and Circular shaped funnels showed a significant impact on the catch rate $(\mathrm{P}<0.05)$ (Table 2$)$. Among the four types of funnels, Oval shaped funnel was found to be more efficient than the other type of funnels with 89 No's/24 soaking days. Whereas in other types of funnels such as Rectangular, Heart-in shaped and Circular Funnels were caught 34 No's, 37 No's and 15 No's for 24 soaking days respectively (Table 1). Based on different months, the Oval funnel was caught the high number of catches in December with 24 No's/4 soaking days and all the months of the study period, the Oval funnel was caught Highest number of catches (Fig. 12). Mariappan et al., (2015) also reported that the rectangular funnel shape rear end opening (342 No's/20 soaking days) had the highest catch rate than elliptical shaped rear end opening (99 No's/20 soaking days). But, Sheaves (1995) reported that the effect of horse neck funnels in reducing escapement tend to retain fish in traps with these funnels, while the fish in traps with straight funnels probably showed escapement more easily. The reason was the posterior end of the Horse neck funnel was kept downwards to retain the fishes. But the present study revealed that the Oval Shaped and Heart-in shaped funnels were found to be more efficient than that of Rectangular and circular shaped funnels. The reason was, the Oval shaped, Heart-in shaped funnels were kept downwards. Among the two funnel designs the traps fitted with, the Oval shaped funnel has shown higher catch. The reason was that the oval funnel facilitated easy entry of fishes. 
Table.1 Catch particulars of trap fitted with funnels having four different shapes of Rear end opening

\begin{tabular}{|c|c|c|c|c|c|c|c|c|c|c|c|}
\hline \multirow{3}{*}{$\begin{array}{l}\text { Sl. } \\
\text { No. }\end{array}$} & \multirow{3}{*}{$\begin{array}{c}\text { Name of the Fish } \\
\text { species }\end{array}$} & \multicolumn{8}{|c|}{ Mouth } & \multirow{2}{*}{\multicolumn{2}{|c|}{ Total catch }} \\
\hline & & \multicolumn{2}{|c|}{$\begin{array}{c}\text { Rectangular } \\
\left(\mathbf{R}_{2}\right)\end{array}$} & \multicolumn{2}{|c|}{ Oval $\left(\mathrm{O}_{2}\right)$} & \multicolumn{2}{|c|}{$\begin{array}{c}\text { Heart-in } \\
\left(\mathbf{H}_{2}\right)\end{array}$} & \multicolumn{2}{|c|}{ Circular $\left(\mathbf{C}_{2}\right)$} & & \\
\hline & & Nos & Kg & Nos & $\mathbf{K g}$ & Nos & Kg & Nos & $\mathbf{K g}$ & Nos & $\mathbf{K g}$ \\
\hline 1 & Acanthurus bleekeri & 13 & 1.7 & 13 & 1.75 & - & - & - & - & 26 & 3.45 \\
\hline 2 & Epinephalus malabaricus & 4 & 0.7 & 11 & 2 & 6 & 1.17 & 3 & 0.54 & 24 & 4.41 \\
\hline 3 & Abudefduf sexatilis & 2 & 0.07 & 3 & 0.11 & 6 & 0.16 & 2 & 0.05 & 13 & 0.39 \\
\hline 4 & Chaetodon collare & 1 & 0.03 & 8 & 0.24 & 4 & 0.12 & - & - & 13 & 0.39 \\
\hline 5 & Heniochus acuminatus & 3 & 0.07 & - & - & - & - & - & - & 3 & 0.07 \\
\hline 6 & Lutjanus rivulatus & - & - & 14 & 1.09 & 3 & 0.57 & - & - & 17 & 1.66 \\
\hline 7 & Parupeneus indicus & - & - & 4 & 0.77 & - & - & 2 & 0.48 & 6 & 1.25 \\
\hline 8 & Plotosus lineatus & 3 & 0.4 & 5 & 0.78 & 7 & 1 & 8 & 1.06 & 23 & 3.24 \\
\hline 9 & Pterois russellii & 2 & 0.22 & 3 & 0.34 & 2 & 0.23 & - & - & 7 & 0.79 \\
\hline 10 & Scarus ghobban & 2 & 0.44 & 8 & 1.45 & 2 & 0.58 & - & - & 12 & 2.47 \\
\hline 11 & Siganus canaliculatus & 4 & 0.5 & 15 & 1.9 & 6 & 0.68 & - & - & 19 & 3.08 \\
\hline 12 & Zebrasoma veliferum & - & - & 2 & 0.1 & - & - & - & - & 2 & 0.1 \\
\hline 13 & Cheilinus undulatus & - & - & 3 & 1.25 & - & - & - & - & 3 & 1.25 \\
\hline 14 & Plectorhinchus chubbi & - & - & - & - & 1 & 0.6 & - & - & 1 & 0.6 \\
\hline & Total & 34 & 4.13 & 89 & 11.78 & 37 & 5.11 & 15 & 2.13 & 175 & 23.15 \\
\hline
\end{tabular}

Note: Catch expressed for 3 chambers/24 soaking days

Table.2 Analysis of variance of catch rate of different species and the impact of the funnel on catch rate

\begin{tabular}{|c|c|c|c|c|c|c|c|}
\hline $\begin{array}{l}\text { Source of } \\
\text { variation }\end{array}$ & $\begin{array}{l}\text { Degree of } \\
\text { freedom }\end{array}$ & $\begin{array}{l}\text { Sum of } \\
\text { square }\end{array}$ & $\begin{array}{l}\text { Mean } \\
\text { sum of } \\
\text { square }\end{array}$ & F ratio & \multicolumn{2}{|l|}{ F table } & P value \\
\hline Species & 9 & 155 & 17.2 & 4.9 & 2.83 & 2.10 & $\mathrm{P}<0.01$ \\
\hline Funnel & 3 & 118 & 39.3 & 3.1 & 4.57 & 2.95 & $\mathrm{P}<0.05$ \\
\hline Error & 27 & 337 & 12.5 & & & & \\
\hline
\end{tabular}


Fig.1 Description of the study area (Lat: $09^{0} 14.141^{\prime} \mathrm{N}$; Long: $079^{0} 09.433^{\prime} \mathrm{E}$ )
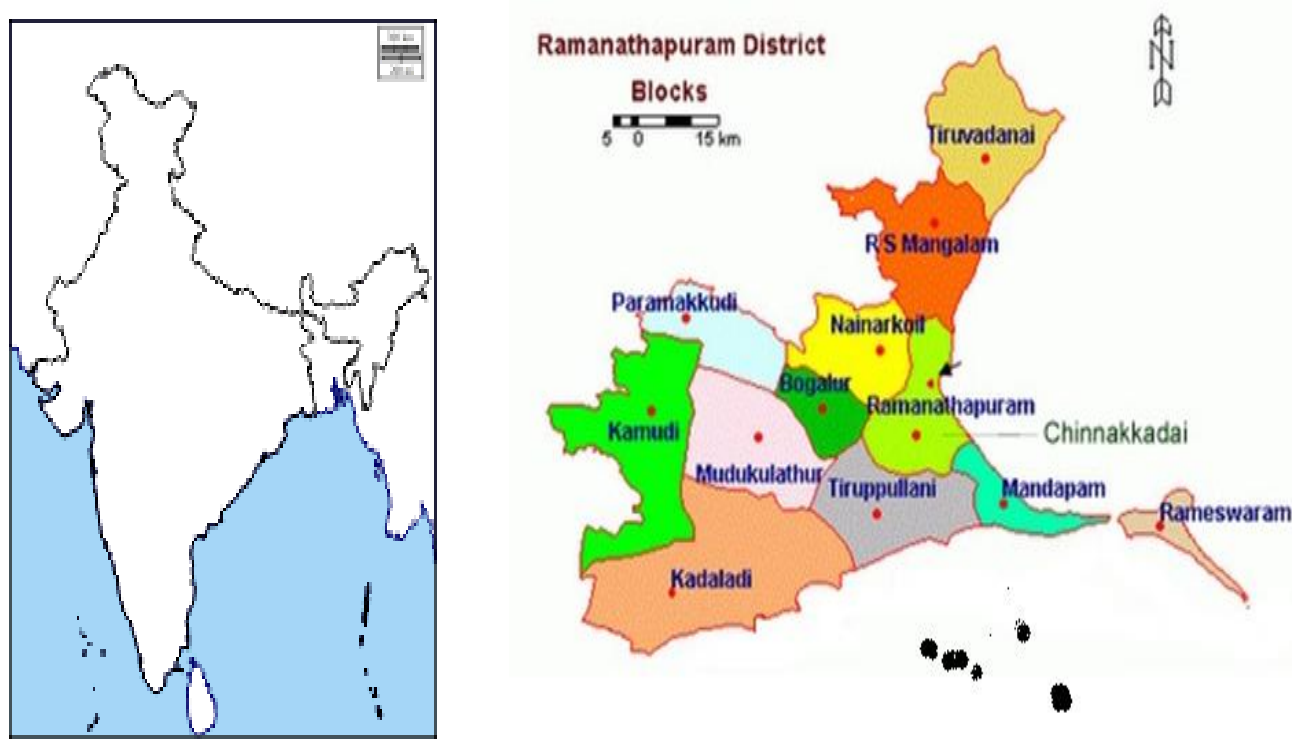

Fig.2 Experimental serial collapsible fish trap with Rectangular and Oval shaped rear end mouth opening (Unit 1)

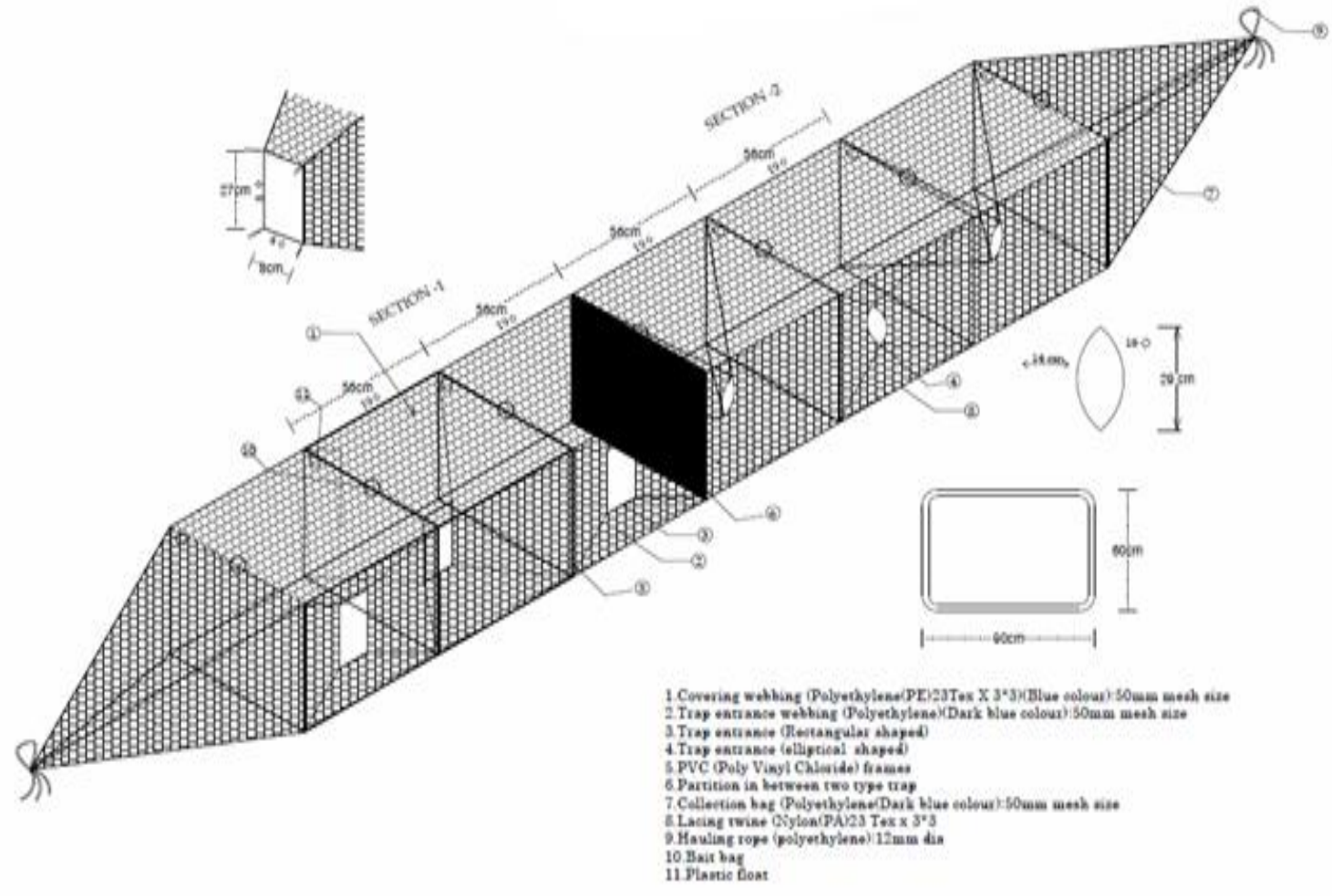


Fig.3 Experimental serial collapsible fish trap with Heart-in and Circular shaped rear end funnel opening (Unit 2)

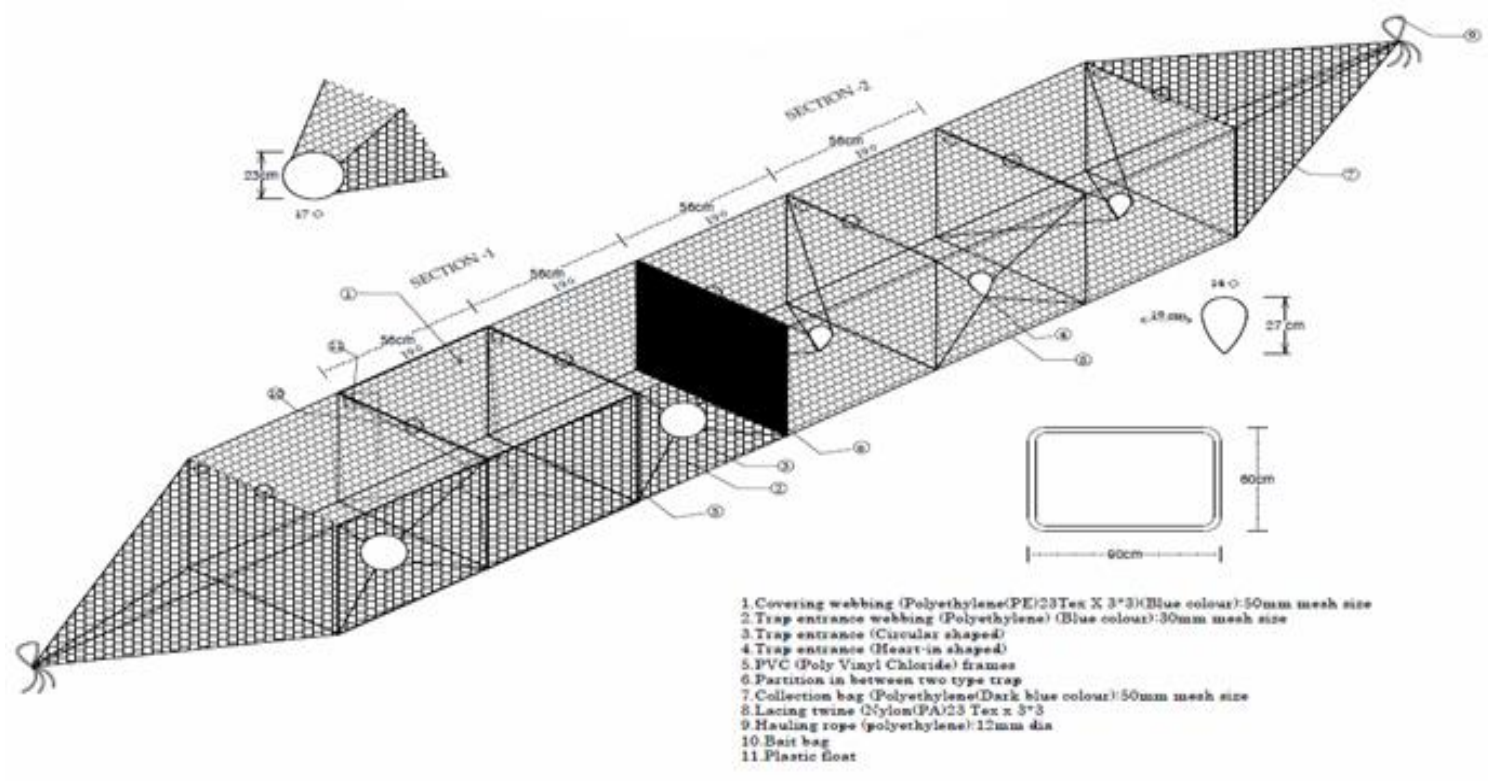

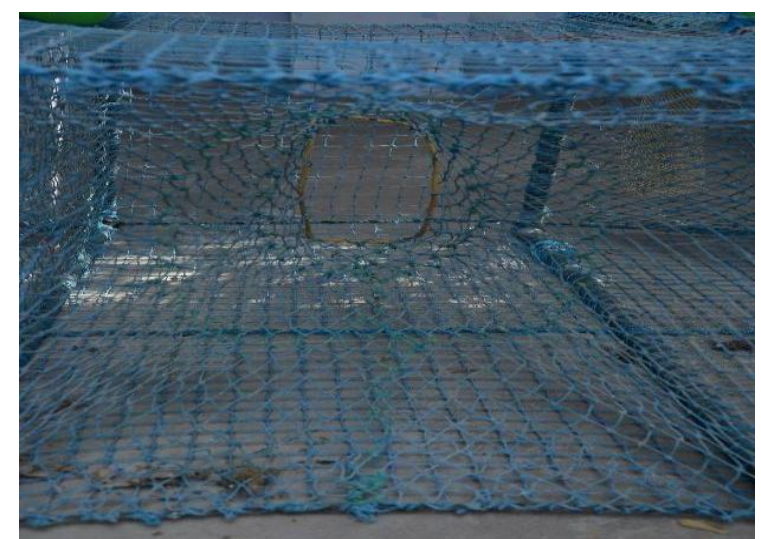

Fig.4 Rectangular funnel

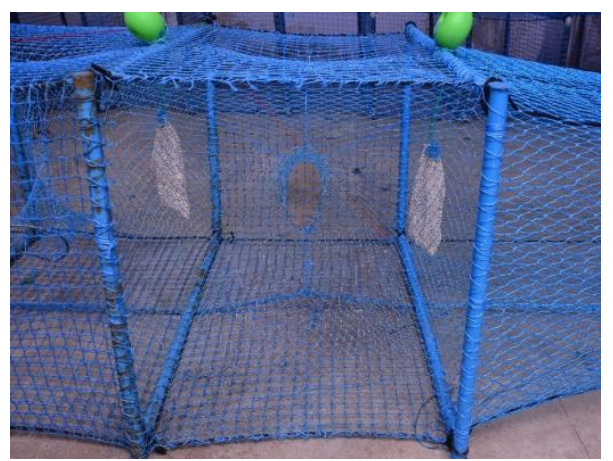

Fig.6 Heart-in shaped funnel

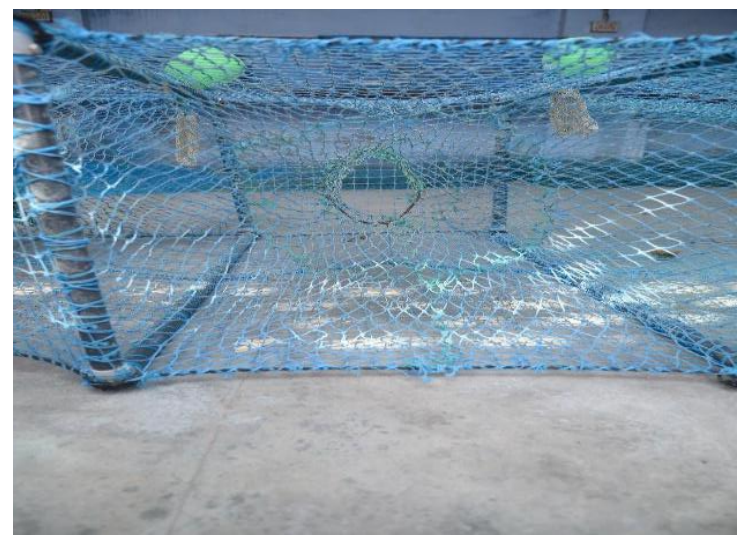

Fig.5 Oval funnel

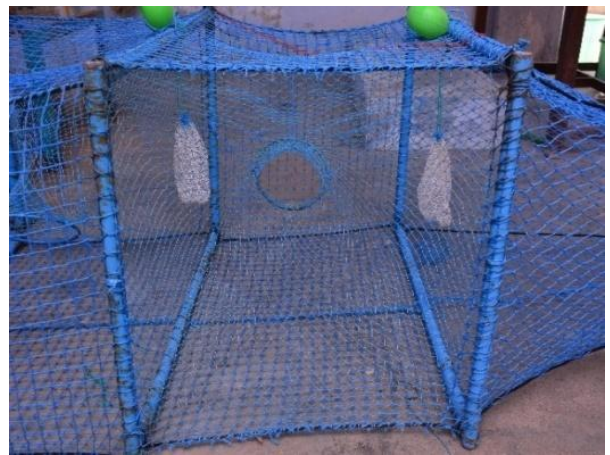

Fig.7 Circular funnel 
Fig.8 Funnel design details of an experimental fish trap with the rectangular rear end funnel opening

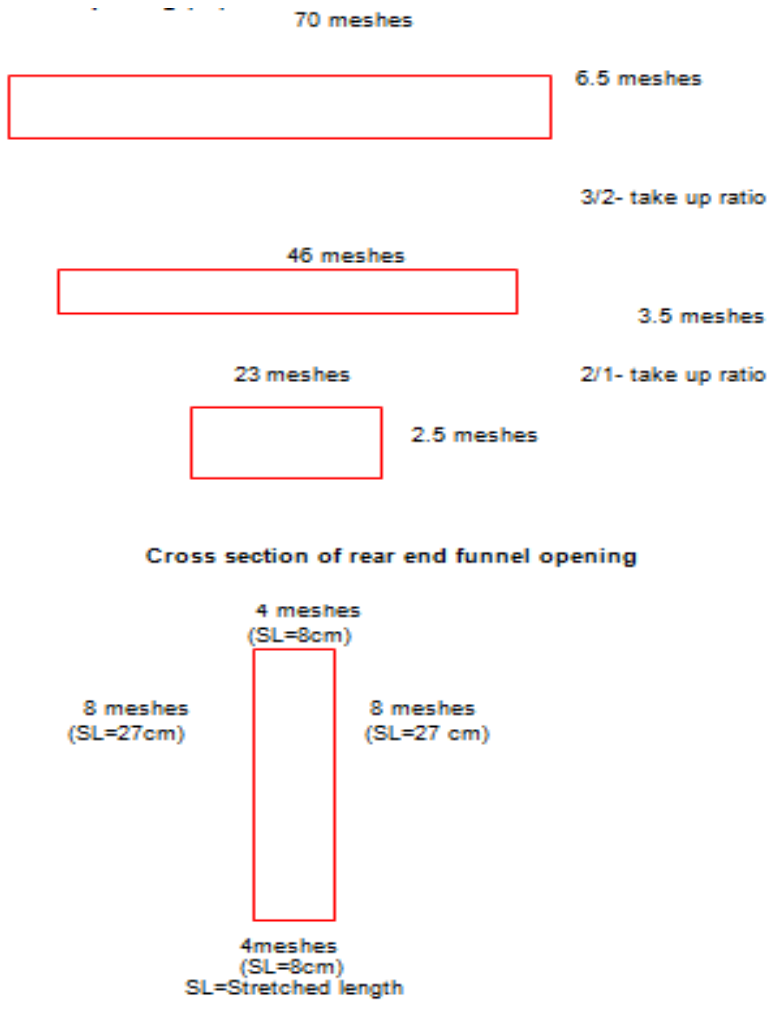

Fig.9 Funnel design details of the experimental fish trap with the oval-shaped rear end funnel opening

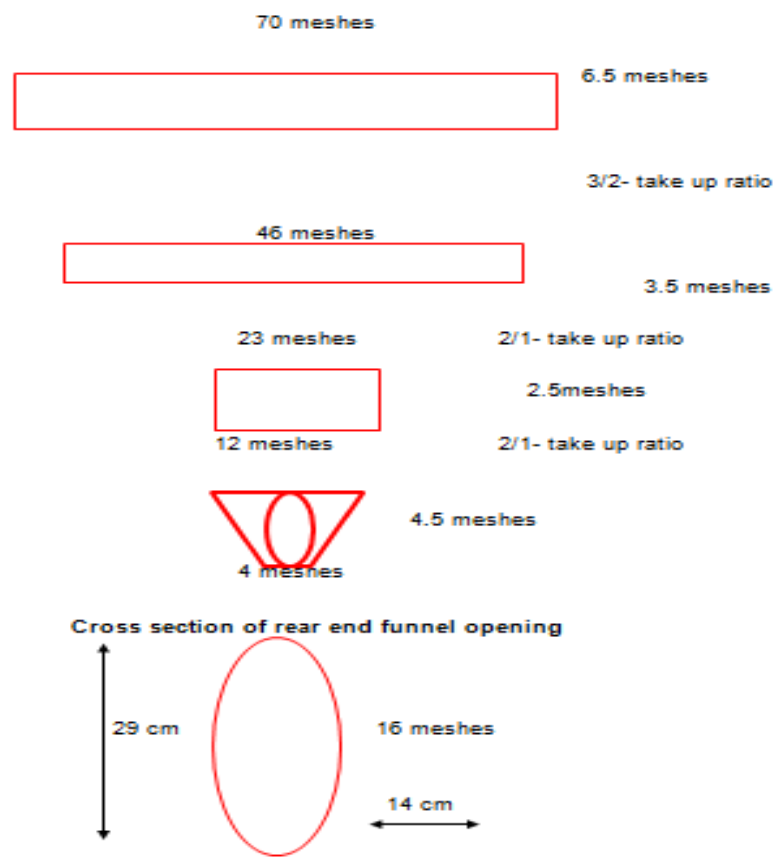


Fig.10 Funnel design details of an experimental fish trap with Heart-in shaped rear end funnel opening

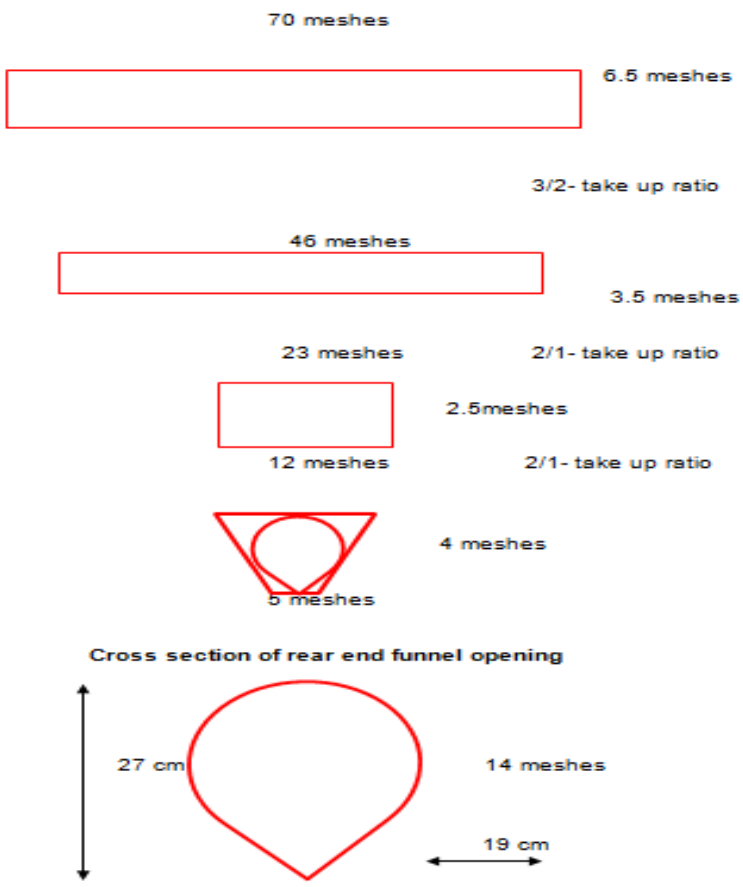

Fig.11 Funnel design details of an experimental fish trap with Circular shaped rear funnel opening




Fig.12 Catch particulars of trap fitted with funnels having different rear end mouth opening during different months

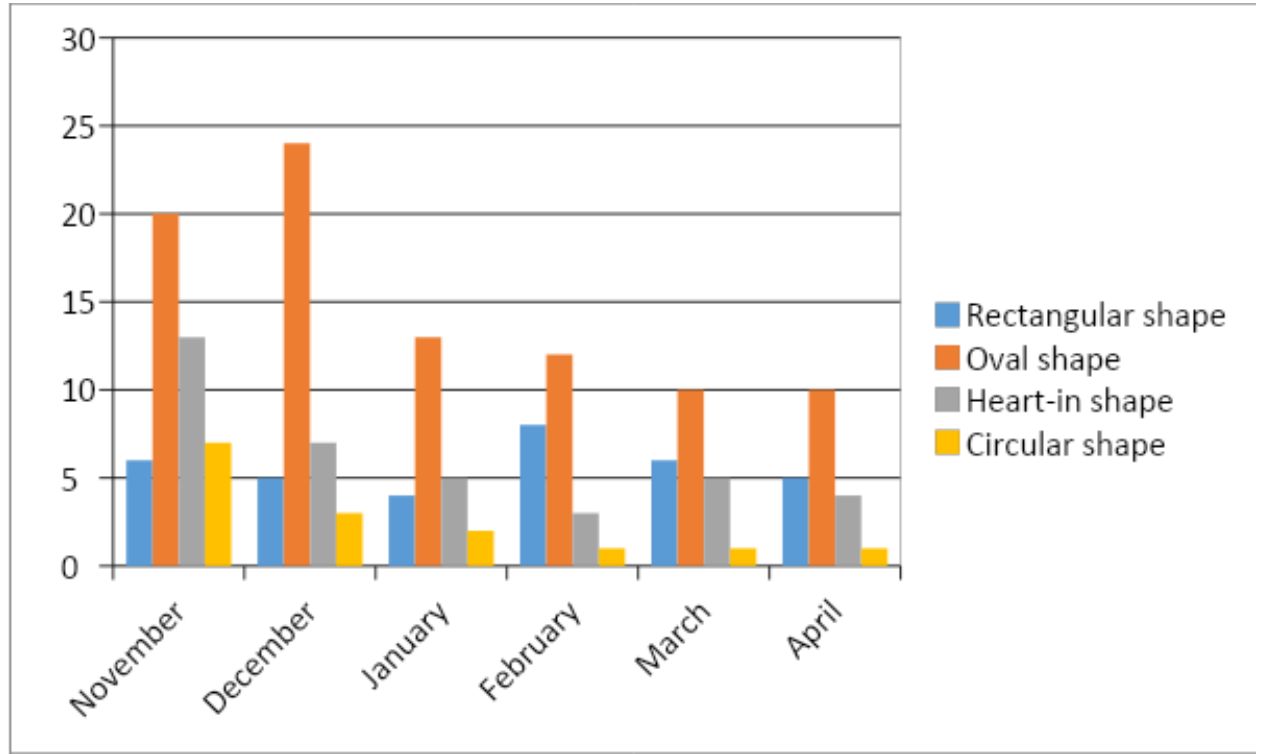

Although the circular shaped funnel also kept downwards, due its high radius the fishes were easily escaped. It may be concluded that Oval shaped funnel with the rear end perimeter of $700 \mathrm{~mm}$ is ideal for serially collapsible fish traps.

\section{Acknowledgment}

The authors record a deep sense of gratitude to Mr. Manimaran, the fisherman of Mandapam for his continuous help in conducting the fishing trials and the financial assistance rendered through ICAR development grant of FC\&RI, Thoothukudi (2015-16) for the fabrication of experimental traps is acknowledged.

\section{References}

Boutson, et al., 2005. Size and Species selectivity by improving collapsible trap design for blue swimming crab in Thailand. Tokyo University of Marine science and technology, Tokyo, Japan faculty of fisheries, Kaetsart University, Bangkok, Thailand.
Caesar and Oxenford. 2005. Testing a collapsible trap design in the deep demersal fishery of Tobogo, Eastern Caribbean. Centre for Resource Management and Environmental Studies University of the West Indies Cave Hill, Barbados. 117-118

Furevik and Lokkerborgl. 1994. Fishing trials in Norway for torsk (Brosme brosme) and cod (Gadus morhua) using baited commercial pots. fisheries research (Amsterdam) 19: 219-229

Hutubessy and Mosse. 2007. An Experimental Fishing Operation of Collapsible Trap for Capture of Coral Fish. Journal Fish. Sci. IX (2). 267273

Mariappan, et al., 2016. Comparison of catching efficiency of collapsible serial fish traps baited with two different baits., J.Exp.Zool.India Vol. 19, No. !, pp. 597-601

Miller and Stewart. 2009. The commercial fishery for ocean leather jackets (Nelusetta ayraudi, Monacanthidae). Asian fisheries science 22., pp.257-264 
Munro. 1974. The mode of operation of Antillean fish traps and the relationships between ingress, escapement, catch and soak. J Cons Int Explor Mer. 35(3): 337-350.

Olsen, D.A., Dammann, A.E. and LaPlace, J.A., 1978. Mesh selectivity of West Indian fish traps. Mar. Fish. Rev, 40(7): 15-16.
Sheaves. 2014. Effect of Design Modifications and Soak Time Variations on Antillean-Z Fish Trap Performance in a Tropical Estuary. Bulletin of Marine Science. 56(2): 475489,

Stewart and Ferrel. 2003. Mesh selectivity in the New South Wales demersal trap fishery. Fisheries Research. 59: 379392.

\section{How to cite this article:}

Arunjenish, D., N. Neethiselvan, B. Sundaramoorthy, P. Jawahar and Masilan, K. 2019. Comparative Performance of Serial Collapsible Fish Trap Using Different Funnel Designs. Int.J.Curr.Microbiol.App.Sci. 8(08): 20-29. doi: https://doi.org/10.20546/ijcmas.2019.808.004 